\title{
ENTREVISTA A MARIO LOSANO
}

\author{
Manuel Atienza \\ Universidad de Alicante
}

Manuel Atienza: En mi biblioteca particular, tus escritos ocupan más de un estante, y es obvio que ahí no está toda tu producción. Pero antes de hablar del contenido de tu obra me gustaría que nos dijeras algo del motor de la misma. O sea, que nos des algunos datos biográficos que expliquen por qué optaste por la teoría y la filosofía del Derecho, a quiénes consideras como tus maestros, etc.

Mario Losano: Mi generación -la que hoy supera los 65 años- entraba "por casualidad" en la Facultad de Derecho: a la Facultad podía acceder únicamente quien provenía del liceo clásico, y este último no tenía ninguna enseñanza jurídica. Sin embargo, era una óptima escuela, en la cual asistí a cursos que daban óptimos profesores, primero en el Liceo Galvani, en Bolonia, y luego en el Liceo d’ Azeglio, en Turín.

Mi familia se trasladó del Piamonte a Bolonia en los años cincuenta y se quedó allí cinco años, antes de volver a Turín. Estoy convencido de que en los años de Bolonia es donde se formó mi vocación por el estudio. Aunque no por el estudio del Derecho: entonces me interesaba más el comportamiento de los animales que el de los hombres y, en la universidad, frecuentaba las reuniones de la asociación de los naturalistas. La pasión por el estudio de las humanidades llegó por otra vía.

Tenía catorce o quince años cuando empecé a estudiar privadamente alemán con Anselmo Turazza, profesor entonces de latín y griego en el liceo y, después, de literatura alemana en la Universidad de Bolonia: una persona de cultura sin límites que había logrado traducir hasta el intraducible Christian Morgenstern. En el liceo Galvani tuve profesores egregios pero hoy, en el recuerdo, su figura domina mi adolescencia boloñesa. En su estudio de la calle Laura Bassi, aquella "hora” de alemán se prolongaba durante tardes enteras, porque del alemán se pasaba al griego o al francés, y la menor duda, por ejemplo, de latín, se resolvía con consultas minuciosas al monumental diccionario de Forcellini. Mi alegría de aprenderlo todo se reflejaba en su alegría de enseñármelo todo, en un flujo recíproco de confianza total que nunca decayó. Baste una anécdota para ilustrarlo. Cuando en enero de 1959 volví a encontrarlo en Bolonia, después de mi traslado a Turín y de haberme 
matriculado en Derecho, me regaló Die Fragmente der Vorsokratiker de Hermann Diels -un texto muy erudito en griego y en alemán: la doble vía de nuestras incursiones intelectuales- con esta dedicatoria: “A Mario Losano, con la segura esperanza de saludarlo, al cabo de un lustro, como docente de Derecho” Perfecto el target, un poco optimista el timing: ¡y cuanto afecto en los dos aspectos! Siendo aún un muchacho, de Anselmo Turazza aprendí no solo el alemán, sino la dedicación total y gozosa al estudio: dos rasgos que caracterizan, creo, toda mi vida.

En los años sucesivos, los inolvidables profesores del liceo turinés echaron nuevos haces de luz sobre el mundo del saber que se abría ante mí. El severo Mongardi me transcribía a mano, en alemán, las poesías de Hölderlin reconducibles a los líricos griegos que estudiábamos en clase. La aguda e ingeniosa Azelia Arici lograba poner vida en los escritores italianos momificados en los libros de texto. El bondadoso Perrini nos daba inspiradas lecciones de historia y de filosofía para unos pocos, mientras que el resto de la clase se dedicaba a diversas actividades lúdicas (la reforma escolar del neohegeliano Gentile confiaba a un único docente la enseñanza de la historia y de la filosofía: creo que se debe a esta fusión -y a la inteligencia de quien me enseñó ambas materias- mi interés posterior más histórico que analítico por las ciencias sociales). Muchos profesores estaban por encima de la media. También la profesora ayudante de italiano, que se acababa de graduar en alemán y que era timidísima, me impartía un cripto-curso paralelo, gracias a la instantánea complicidad que surge entre germanófilos: la encontraría años después, yo en la editorial Einaudi y ella autora de delicadas y refinadas novelas, además de docente universitaria de alemán medieval.

Este era, por lo tanto, el bagaje con el que llegué a la universidad y, un poco por casualidad, a la Facultad de Derecho: una sólida preparación humanística, unida a la convicción de que ella no me habría dado de vivir (el interés por la biología se había ya atenuado). El puente natural entre un liceo clásico sin Derecho y una Facultad todavía desconocida fue, inevitablemente, la filosofía del Derecho. Asistí así al curso de Norberto Bobbio y participé en su seminario sobre la justicia: fue mi primer examen de mi primer año.

A decir verdad, nuestro primer encuentro personal fue más bien un desencuentro. Se discutía sobre la justicia y a mí se me había asignado la $R e$ chtsphilosophie de Gustav Radbruch. Perdido en la gran aula del anfiteatro, yo trataba de explicar no se qué traduciendo un pasaje de aquel volumen y Bobbio perdió la paciencia-“una característica de la escuela turinesa”, me explicaría años después- y se dirigió a mí así: "Pero, en resumidas cuentas, ¿no sabe leer?” Farfullé que no estaba leyendo, sino traduciendo del alemán. “Ah -refunfuñó calmado- entonces venga a hablarme después de la clase”. 
Era el año 1958. Se iniciaba un coloquio que duraría hasta el 9 de enero de 2004.

M.A.: Cuéntanos algo más sobre tu relación con Norberto Bobbio. ¿Cómo sintetizarías su aportación a la filosofía del Derecho? ¿Has tenido otros maestros además de Bobbio? ¿Quiénes han sido?

M.L.: Las preguntas son dos: una de enorme peso objetivo, sobre la aportación de Bobbio a la filosofía del Derecho; la otra de gran intensidad subjetiva, sobre mis maestros de los años universitarios (puesto que ya he hablado de los de los años pre-universitarios)

A la primera pregunta respondo sólo con pocas palabras. Para los filósofos del Derecho y para los intelectuales italianos, Bobbio fue durante decenios la personificación misma de la filosofía del Derecho, de manera que al tema de su “aportación a la filosofía del Derecho” habría que dedicar un libro. Hoy, sin embargo, prefiero el silencio, porque su muerte ha estado acompañada de una floración demasiado exuberante de más bien improbables discípulos por autodeclaración. Por ello, he publicado en España y en Brasil mis únicas páginas en recuerdo de Bobbio y quizás vuelva a escribir sobre él -en clave no emotiva, sino científica- cuando se haga un poco de silencio.

La segunda pregunta, sobre mis “otros maestros” además de Bobbio, me obliga a confesar que, para responderte, tendría que inventar armoniosas genealogías culturales en buena parte reconstruidas ex post, o bien admitir que nunca he reconocido un príncipe, ni político ni cultural. La culpa es de mi carácter moderadamente anárquico en cuestiones políticas y blandamente insubordinado en las académicas. Nunca me he sentido el continuador de las doctrinas, ni tampoco de las materias, de uno de mis maestros, porque de ellos admiraba la vida ejemplar en el plano sobre todo humano y, después, cultural. Eran y son mis maestros de la vida, no mis maestros de escuela (filosófica). Trato de imitarles en algunos aspectos existenciales. Cultivo algunos de sus filones de investigación, que combino en una pantagruélica visión del saber, puesta a prueba por medio de cualquier posible verificación de la realidad.

¿Se me asigna una tesis de licenciatura sobre las constituciones de las repúblicas populares europeas? Yo aprendo rumano y voy a Bucarest y, después, a la República Democrática Alemana para ver cómo están realmente las cosas. ¿Parece, al final de la guerra de Argelia, que los “Conseils de Revision” cometen favoritismos al enviar a los conscriptos franceses al Norte de África? Yo me siento en el "Conseil” del cuartel de la Place Verdun, en Grenoble, donde la comisión debe efectuar indagaciones antes de establecer que el reglamento no admite público en los “Conseils de Revision”. ¿Des- 
cubro la informática con un cierto desconcierto por parte de los colegas juristas? Durante meses, en Tokio, me hago describir por los protagonistas el milagro informático de Japón y, un año después, ilustro las mirabilia informaticae en Brasil. ¿Pero cómo puede estudiarse la automatización de un Derecho en Asia Oriental y en Sudamérica sin estudiar la historia de esos Derechos? Nacen así mis primeras investigaciones sobre la historia jurídica de esos continentes. Y, después, ¿cómo se puede estudiar informática sin conocer su historia? Nacen así mis estudios de historia tecnológica, desde los autómatas árabes del siglo XIII, hasta los engranajes de Charles Babbage, en el XIX. En fin, si las ideologías se han terminado en Europa, ¿qué es lo que mueve a las masas de campesinos sudamericanos? Así es como hoy me encuentro inmerso en el "Movimiento de los sin tierra" brasileños. "Practico, en suma, un realismo modesto y caritativamente ecléctico": así había definido mi método de investigación con ocasión del doctorado honoris causa en Hannover.

M.A.: Más adelante abordaremos el tema metodológico. ¿Podemos volver ahora a los años del aprendizaje académico?.

M.L.: Esos viajes de descubrimiento no cancelaban, sin embargo, las actividades académicas tradicionales y, por ello, al lado de ellos, tomaban forma las traducciones, las ediciones filológicas y las investigaciones sobre Kelsen, Jhering y Hohfeld. Bobbio no era demasiado entusiasta de esta gitanesca aproximación mía a la ciencia. Fue memorable la reprimenda que recibí en 1969, después de la publicación de Giuscibernetica, al final de una de las “reuniones del miércoles” de la editorial Einaudi, en la que habíamos participado ambos. Nuestros coches estaban aparcados uno al lado del otro, en la calle bajo la ventana de la editorial, y ambos -con las puertas abiertas y un pie ya en el coche- seguíamos discutiendo: "No hay que llevar a la imprenta temas que aún no están maduros”, me recriminaba Bobbio. “iPero a mí me interesan precisamente porque no están maduros!”, me defendía yo.

Sobre estas heterogéneas vías del saber he tenido guías inolvidables: y tengo el atrevimiento de creer que su espíritu sigue benévolamente en la parte de las mismas que continúan viviendo en mi obrar, si no por otra cosa, por la honestidad con que lo practico. ¿A quién recordar además de a Bobbio? Ante todo a Renato Treves, numen tutelar de mi atolondrada carrera universitaria pero, sobre todo, presencia tan intensamente amiga que, después de su muerte, la universidad milanesa me parece una cáscara vaciada de vida. A él le debo mi primera cátedra y la primera publicación sobre la iuscibernética en 1968. Alessandro Galante Garrone reforzó en mí el sentido histórico, la visión reformista de la lucha política y la civilidad del debate. Gracias a él, “Il Ponte” de Florencia publicó mis primeros escritos. Ales- 
sandro Passerin d' Entrèves -presidente de la Internationale Vereinigung für Rechts-und Sozialphilosophie cuando yo fui secretario general- me dirigió hacia una visión más crítica de Kelsen y me abrió las puertas del mundo anglo-americano. A él le debo la larga estancia en la Yale Law School y el descubrimiento de Hohfeld.

Pero mis guías no venían solo de la "pequeña patria” del Piamonte. Si Alessandro Passerin d’ Entrèves me abrió las puertas del mundo anglosajón, al menos otros tres San Pedros usaron para ventaja mía las llaves de otros tantos mundos de los que eran custodios. El orientalista Fosco Mariani guió con paciencia infinita a un niponista aficionado como yo, armado solo de entusiasmo y de curiosidad. El literato Tudor Vianu puso orden en mis fragmentarios estudios balcánicos y, en política, me mostró cómo era posible (y lo difícil que era) permanecer libre adentro, mientras que afuera estaba la dictadura. A Rumania dediqué mi primer escrito en "Il Ponte" en 1961. En fin, el último de mis guías aún vive: tiene 95 años y es Miguel Reale, el patriarca de la filosofía del Derecho sudamericana, que, desde hace más de treinta años, apoya mis estudios sobre aquel continente y que ya en 1973 abrió su Facultad de São Paulo a la informática jurídica. Una foto de entonces nos muestra junto al primer terminal que entró en el aula magna de la Facultad del Largo Sao Francisco.

Estos son, pues, mis viejos maestros de la vida y, en el recuerdo, cada uno de ellos se me aparece como un retrato singular a tamaño natural. Pero no es sólo a través de su herencia como la vida toma forma y dirección. Después de ello aparece la bien estructurada foto de grupo de algunos de mis coetáneos y, lentamente, el recuerdo ejemplar del maestro de la vida se muda en la confortante presencia del grupo de los amigos: ¡cuántos españoles, sudamericanos y alemanes entre ellos! Aparecen, en fin, las recientes instantáneas de los más jóvenes que abren las ventanas sobre paisajes futuros: son tierras en las que ya no podré aventurarme, pero cuyo carácter inalcanzable no las vuelve menos fascinantes. De todas formas, donde yo no llegue ya, llegarán otros: los hay muy buenos y muy buenas. Confucianamente, tengo el presentimiento de poder ser su discípulo en una de mis próximas existencias.

M.A.: Tu has sido uno de los pioneros de la informática jurídica en Italia y en Europa. Me gustaría que nos dijeras cuáles consideras que han sido tus principales contribuciones en la materia y cómo ves el presente y el inmediato futuro de este conjunto de disciplinas, la iuscibernética, que has contribuido a fundar. ¿Qué consejo le darías a un joven que se propusiera trabajar hoy en informática jurídica? 
M.L.: Han pasado más de 20 años, cuando el primer número de DOXA, en 1984, me planteaba la pregunta: "En qué áreas has trabajado? ¿Cuáles han sido los factores que te han llevado a desplazar tu interés de una a otra área?”. Entonces contestaba contando el origen de mi interés por la aplicación de la informática al Derecho y exponiendo mis previsiones sobre sus posibles desarrollos. Hoy, DOXA, número 28, me pide, por el contrario, el balance agridulce del brillante pasado que tengo a las espaldas. En síntesis, diré: mi interés por la informática jurídica continua inalterado, mientras que mis previsiones han tenido que confrontarse con desarrollos en parte inesperados y en parte frustrantes. Pero procedamos con orden, siguiendo los temas propuestos en la pregunta.

Espero haber hecho contribuciones tanto teóricas como prácticas a la informática jurídica en Italia. En el plano teórico, como perteneciente a la primera generación de juristas informáticos -es decir, la que tuvo que "inventarse” la disciplina-, he tratado de distinguir la aplicación de la informática al Derecho (es decir, la informática jurídica en sentido estricto), de la aplicación del Derecho a la informática (es decir, el Derecho de la informática), una disciplina técnica, la primera, y jurídica, la segunda. Esta organización de la disciplina que estaba naciendo, ya anunciada en la Giuscibernetica de 1969, tomó cuerpo luego en mi Corso de informatica giuridica: en 1971, la primera edición constaba de un solo volumen; en 1981, los dos volúmenes de la segunda edición introducían una distinción que luego se afianzaría, pues se dedicaba, el uno a la Elaborazione dei dati non numerici (traducido al español en 1984 por Aguiló, Atienza y Ruiz Manero) y otro al Diritto dell' informatica. En 1984, esta segunda edición se completó con L'analisi delle procedure giuridiche, en donde proponía una edición de las normas compatible con la informática. En fin, en 1985-86 publiqué los tres volúmenes que sistematizaban toda la materia: un volumen técnico, Informatica per le scienze sociali, y dos volúmenes jurídicos, Il diritto privato dell' informatica y Il diritto publico dell' informatica. Después de esta fecha, la rápida evolución tanto de la tecnología como del Derecho ha hecho imposible una actualización de este trabajo por parte de una sola persona.

En el plano práctico, mis realizaciones se refieren, en primer lugar, a los bancos de datos jurídicos, tanto legislativos como judiciales. Nació así, en 1973, el primer banco de datos legislativos de Lombardía, destinado sin embargo a disolverse al pasar de la fase experimental a la de gestión. Este era el problema típico de aquellos inicios: los prototipos geniales no se transformaban casi nunca en servicios para el ciudadano y hoy, en el fondo del Gran Mar Océano de la Informática Jurídica, yacen muchos galeones con sus bodegas llenas de ideas doradas y olvidadas. Por ello, la pasión por las (demasiadas) novedades tecnológicas no debe hacer olvidar la historia de la 
informática jurídica: en treinta años, los problemas jurídicos a resolver han quedado con frecuencia inalterados, de la misma manera que las soluciones pioneras del pasado todavía pueden ofrecer indicaciones útiles incluso en tiempos de tecnologías pasmosas. En aquel banco de datos legislativos en línea coloqué en 1987 el primer CD-ROM italiano con sentencias de segundo grado del área milanesa. Puesto que ese banco de datos judiciales no en línea iba por delante de su mercado potencial, su contenido se hizo desembocar en el sistema Italgiure de la Corte di Cassazione.

Estas realizaciones prácticas no habrían sido posibles sin los constantes contactos con las casas constructoras de ordenadores, que al comienzo de la era informática también eran productoras de los programas a ejecutar. Seguí los primeros cursos de programación en la sociedad Honeywell, colaboré con la sociedad IBM (que puso a mi disposición personas, programas y tiempo-máquina para realizar los primeros proyectos de information retrieval legislativa, en los años setenta), y también con Olivetti y con Univac. Pero la colaboración más duradera y el recuerdo más intenso están ligados a la rama informática de la sociedad Siemens, donde encontré durante años un incomparable ambiente de trabajo y de investigación, en Italia y en Alemania. Bajo las alas de "Mamá Siemens”, nacieron no sólo las aplicaciones al Derecho, a las bibliotecas y a los catastros, sino también mis libros sobre la historia del cálculo mecánico: las monografías sobre Leibniz, Babbage, Scheutz y Zuse publicadas por la editorial Etas Kompass, al principio como inteligentes aguinaldos empresariales para Navidad, y después como volúmenes distribuidos también en las librerías. Entre los años setenta y ochenta se perfiló en el horizonte y se desvaneció también el sueño del ordenador europeo, cuando las empresas europeas trataron de colaborar constituyendo la sociedad "Unidata”, muy pronto deshecha por los corrosivos intereses nacionales. El “ordenador europeo” no vio la luz y, en particular, Italia perdió el tren de la informática: Lorenzo Soria se doctoró conmigo presentando la tesis Informática, ocasión perdida, publicada en 1979 por Einaudi. De esos años de provechoso trabajo, pero también de ilusiones hoy casi olvidadas, me quedan los proyectos realizados y, cosa rara, los vínculos de amistad robustecidos en un ambiente de trabajo para mí irrepetiblemente constructivo.

En conclusión, en el ámbito de la informática jurídica en sentido estricto, estoy convencido de haber cumplido con mi tarea fundamental de docente universitario: proyectar la innovación y ofrecérsela a los potenciales usuarios al puro precio de coste. Si después los usuarios potenciales duermen, no es tarea de la universidad sacarles de su letargo o sustituirlos en la gestión: la universidad no es una empresa, aunque hoy se pretenda hacer creer que lo es. 
En el ámbito del Derecho de la informática me he comprometido a fondo a fin de que Italia se diera una ley sobre la privacy. Desde 1977, he publicado artículos de comparación con las leyes extranjeras sobre la privacy, he analizado los efímeros proyectos de ley italianos, he traducido en italiano incluso la ley española entonces en vigor (la Lortad), y hasta he propuesto un proyecto de ley sobre la privacy. Todo inútil: Italia fue el penúltimo de los Estados de la Unión Europea en dictar esa ley, en 1996.

Contribuí todavía a un comentario de esa ley, y después la abandoné a su destino: ahora debía ocuparse de ella no ya el teórico del Derecho, sino el jurista de empresa, el abogado, el juez o el burócrata. Sin embargo, puesto que con la privacy de la gente honesta se tutelaba también la de los malhechores, muchos protestaban contra el hipergarantismo de aquellas normas. Por ello, mi interés por la política legislativa acerca de la privacy se ha trasladado al conflicto entre la tutela de la privacy y la tutela de la seguridad: ya antes de la lucha contra el terrorismo, en efecto, se había planteado el problema de la lucha contra la criminalidad organizada. Hoy me parece necesaria una revisión de la actual tutela jurídica de la privacy: pero éste no es momento para hacer frente a una cuestión tan espinosa. Con los atentados de Londres y de Sharm el Scheik de julio de 2005 está ya claro que hay en curso una guerra contra la libertad y los derechos fundamentales propios de Occidente: pero, paradójicamente, una de las primeras medidas bélicas de los Estados occidentales deberá ser precisamente la limitación del derecho fundamental a la privacy.

Entre tanto, en la construcción de los bancos de datos, me tropecé continuamente con leyes mal formuladas, que impedían que se pudieran encontrar de manera plena las informaciones legislativas, o bien que obstaculizaban la automatización de la administración pública (así se llamaba, en sus orígenes, el actual e-government). Estas dificultades y los ejemplos extranjeros de leyes compatibles con la informática reforzaron desde 1971 mi interés por las técnicas legislativas, hasta el punto de que en el futuro querría introducir en las Facultades de Derecho la asignatura "técnica de redacción de textos jurídicos”. Hemos llegado así al tema de la didáctica y, en particular, a la enseñanza de la informática jurídica.

Durante 35 años he tratado de introducir la informática jurídica en sentido amplio (que incluye también el Derecho de la informática) en la Università degli Studi de Milan, en donde enseñé desde 1969 hasta 2004, pero -con la única excepción de Renato Treves- siempre encontré un desinterés total por esa enseñanza. Ni siquiera dos mandatos como presidente del centro de cálculo de toda la universidad abrieron una brecha en esa muralla. La pasión intelectual me transformó en pusher académico: durante años he ido 
despachando módicas cantidades de informática jurídica bajo la cubierta de la teoría general del Derecho.

En 1992 me llegó la propuesta de dirigir en Florencia el Istituto per la Documentazione Giuridica del CNR, la única entidad de investigación en Italia que entonces se ocupaba de informática jurídica. Innovar un equipo de funcionarios públicos inamovibles con un mandato limitado a cuatro años era una empresa desesperada, pero también un hermoso reto. Sin embargo, cuando llegó al Consejo científico un profesor de Derecho romano que quería abolir el uso del inglés, dimití a mitad de mandato. Vino luego una cuestión parlamentaria sobre mi dimisión, después la dimisión del único docente de informática del Consejo científico. En fin, todo volvió a la situación anterior.

Mis vicisitudes en Milán y en Florencia son dos ejemplos mínimos del estancamiento que ya dura decenios en Italia no sólo en la investigación, sino en casi todos los campos. Cuando en los años sesenta llegué a Milán encontré allí la capital italiana de la actividad editorial y de la informática: mi habitat ideal. Hoy, la actividad editorial es puramente comercial y la informática ya no existe. No existe tampoco el Milán que había aprendido a amar; hoy comparto más bien el juicio del politólogo del XIX Giuseppe Ferrari, que la definió como una ciudad “pomposamente estéril”. Por lo tanto, ¿por qué quedarse en Milán?

En 2001, la Universidad del Piamonte Oriental (que tiene su sede en tres ciudades en el límite entre Lombardía y Piamonte) me ofreció la posibilidad de organizar un curso trianual de informática jurídica en la sede de Alessandria, a dos pasos de la ciudad donde nací y de mi casa de campo. Las asignaturas de informática constituyen el $40 \%$ de las enseñanzas y las jurídicas el 60\%: por tanto, en base a las reglas ministeriales, quien termina este curso es un jurista que puede acceder al bienio de especialización y, después, a las tradicionales profesiones forenses. Pero se llega a ellas sabiendo informática: de hecho, el curso es "interfacultativo”, es decir, sirve para la Facultad de Derecho y para la de Informática. Y cada uno hace su trabajo: los juristas enseñan el Derecho y los informáticos la informática. A cada materia jurídica se le añade un módulo informático (por ejemplo, al "Derecho penal” se le añade "Derecho penal de la informática”) y a cada materia informática se le añade un módulo jurídico (a "bases de datos” se le añade "bases de datos jurídicos”).

Este año se gradúan en Alessandria los primeros juristas informáticos. Los que terminen el bienio posterior podrán hacer también un máster europeo en Hannover, en el Institut für Rechtsinformatik. Este instituto (al que considero también un poco mío) ha construido una valiosa red europea en el curso de sus laboriosos 20 años de investigación, es decir, en los 20 años en 
los que en Milán se meditaba sobre la eventual existencia de la informática jurídica.

Si se añade que en esa ciudad "pomposamente estéril" la universidad me ha sido inexplicablemente hostil, se puede comprender por qué desde 2004 me he trasladado a Alessandria, a la Facultad de matemáticas, pero al departamento de Ciencias jurídicas y económicas: una situación híbrida que responde bien a mis exigencias de jurista tanto informático como humanista. Hic manebimus optime o, por lo menos, así lo espero.

M.A.: ¿Y cómo ves el presente y el inmediato futuro de la informática jurídica?

M.L.: Esa pregunta tiene fácil respuesta: la informática es ahora omnipresente; hasta tal punto es así que Italia tiene un ministerio al respecto que se ocupa del e-government; los abogados se ha dado cuenta de que los asuntos informáticos son rentables y cada vez más numerosos; los jueces se dan cuenta de que no pueden delegar en los peritos las decisiones de los casos informáticos; las empresa, en fin, tienen necesidad en todos los niveles de profesionales que sean, al mismo tiempo, usuarios y suministradores de datos informáticos. Por lo tanto, la informática jurídica está destinada a afianzarse cada vez más, porque -en el mítico “mercado”- hay una demanda de juristas informáticos.

Sobre esta constatación se basan también los consejos que daría al estudiante interesado en la informática jurídica. Esta elección le abre ciertamente un amplio mercado de trabajo, pero con dos condiciones: la primera es que tenga un curriculum de informática “en serio” (es decir, articulado y no autodidacta), manteniéndose constantemente actualizado, después de haber cursado sus estudios, tanto en la tecnología como en el Derecho; la segunda es que ya en los años de estudio se cree una red internacional de corresponsales (también para esto sirve el máster de Hannover, por ejemplo), porque los problemas de informática jurídica son por su naturaleza problemas que a veces han encontrado ya una solución en el extranjero o que exigen una solución transnacional.

¡Ah!, casi olvidaba un último consejo: aprender muy bien el inglés, aunque un profesor de Derecho romano fuera del parecer contrario.

M.A.: Lo que antes has dicho sobre tu paso a la Facultad de Matemáticas es una muestra de tu vocación transdisciplinar, pero quizás también de que algo no va del todo bien en la universidad italiana. ¿Cómo ves la universidad en Italia y en los otros países con los que has tenido un contacto académico en los últimos años? ¿Qué papel están jugando -o pueden jugar en el futuro- las Facultades de Derecho en el conjunto de la universidad? 
¿Qué piensas sobre el llamado “espacio de Bolonia”? ¿Cómo ves el futuro de la filosofía del Derecho en cuanto disciplina académica?

M.L.: Hablando de la universidad italiana, decir que "algo no va del todo bien” me parece un cortés eufemismo. Hace más de diez años describí la crisis de la universidad italiana en el artículo La universidad de Bronxford un instante antes del colapso ("Boletín de la Institución Libre de Enseñanza", 1994, pp. 45-55), diciendo que en ella se buscaba la excelencia de Oxford con métodos del Bronx. Bien, hoy diría que la búsqueda de la excelencia se ha abandonado; lo que queda es el Bronx y estamos en el colapso. Faltan las personas, faltan los fondos, falta una visión de la universidad en el contexto de la sociedad italiana. He valorado positivamente la reforma nacida en 1999 del encuentro de los rectores europeos en Bolonia porque, a pesar de sus límites, permitía innovar: precisamente, gracias a esa reforma he logrado que naciera el trienio de informática jurídica en Alessandria. Pero, pasando de mi afortunado caso específico a la situación general, el estado actual de la universidad italiana roza el absurdo. He aquí una síntesis.

La reforma “de Bolonia” ha transformado la tradicional carrera de cuatro años de Derecho en tres años, seguidos de otros dos de especialización. Del trienio inicial se puede pasar directamente al mundo del trabajo, o bien continuar con el bienio. Está claro que el tipo de enseñanza debería ser distinto en base al tipo de trienio: el Derecho penal, a un estudiante que irá pronto a trabajar (y no podrá llegar a ser ni juez ni abogado), se le debe enseñar de manera distinta que al que podrá profundizar en el Derecho penal durante el bienio (y podrá llegar a ser juez o abogado). Con la reforma se necesitaban, por lo tanto, más docentes; y la reforma preveía también instrumentos de noble precariado universitario como, por ejemplo, docentes con contrato pro tempore provenientes del mundo de la economía divinizado por los gobiernos neoliberales.

Sin embargo, la reforma "de Bolonia" tuvo que realizarse en un periodo de grave crisis económica, de manera que durante años se redujeron drásticamente los fondos que el Ministerio transfiere a las universidades públicas. Incluso un Departamento bien administrado está obligado a enviar un correo electrónico en el que se habla del techo anual de gastos: "Cada miembro del departamento podrá gastar hasta 30 euros en envíos postales [...] Agotado el mencionado presupuesto, cada docente podrá sin embargo hacer uso del servicio postal adquiriendo más sellos con cargo a sus propios fondos de investigación”. Llamar "presupuesto” a los 30 euros anuales de franqueo postal es una perversión lingüística de la cual el Ministro que nos obliga a ello deberá dar cuenta el día del juicio final. Dadas estas restricciones, por lo tanto, desde el comienzo no sólo faltó el dinero para los nuevos 
docentes, sino que directamente quedaron bloqueados los nombramientos de los docentes que ya habían ganado un concurso de cátedra. También se bloqueó la incorporación del personal no docente. Este bloqueo total del personal dura ya tres años, con la consecuencia de que departamentos con una treintena de docentes disponen de dos o tres personas para la secretaría y la contabilidad.

El resultado de conjunto es digno del mejor Ionesco. Los alumnos del trienio -independientemente de lo que quieran hacer al finalizar- siguen las mismas lecciones del mismo docente y tienen, de hecho, el mismo examen, a menos que los estudiantes del trienio de orientación profesional no resulten agraciados con una "rebaja” de las páginas a estudiar. De todas formas, los estudiantes-brahamanes que se han inscrito en el trienio de "Ciencia jurídica” (preparatorio del bienio de especialización) acceden directamente al bienio, mientras que los estudiantes-paria del trienio de orientación profesional de "Servicios jurídicos" acceden a él sólo después de algunos exámenes adicionales. Sin embargo, todos son doctores: doctores "iunior” todos los que acaban el trienio; y doctores “con maestría” los que completan los cinco años.

El teatro del absurdo encuentra una continuación en la "reforma de la reforma” de mayo de 2005, la cual -para ponerse a cubierto del embrollo de los trienios- prevé un "recorrido en Y" para las Facultades de Derecho. El primer año será común a todos; después, el que quiere ir pronto a trabajar hará otros dos años de orientación profesional, mientras que los otros estudiantes acudirán a un periodo cuatrianual de más alto nivel. Pero siguen faltando los fondos y continúa el bloqueo del personal: por tanto, el "recorrido en Y” se volverá a encontrar en la misma situación del actual "trienio más bienio”, es decir, no habrá los medios para diferenciar los itinerarios didácticos, que entre tanto con la reforma de la reforma -adviértase- de dos se han convertido en tres.

Pero la universidad no es un hortus conclusus. La crisis de la universidad italiana es uno de los aspectos de la crisis de una sociedad civil que no tiene un proyecto y que, por tanto, envejece rápidamente ante la dramática evolución de los últimos dos decenios. Precisamente por esta razón, ya no existe la gran industria italiana: la química y la informática italianas han desaparecido; de la mítica Olivetti no existe ya ni la marca; la Fiat está al borde de la quiebra; a Alitalia se la mantiene en vida con la respiración boca a boca de las subvenciones estatales, las cuales, además, están en el punto de mira de la Unión Europea. No le va mejor a la pequeña y mediana industria: el sector textil y el zapatero han sido puestos de rodillas por China; en estos días ha cerrado las puertas en Milán la última fábrica italiana de televisores. Italia está a la cabeza de la clasificación mundial de usuarios de 
teléfonos móviles, pero no produce ni uno. Esto sucede porque la industria italiana sigue produciendo a precios alemanes bienes que hoy saben hacer igual de bien los malasios o los eslovacos. En este contexto, un gobierno sin blanca aconseja a la universidad pública pedir fondos al "mercado” el cual, sin embargo, se está hundiendo. No hay que extrañarse de que también la universidad italiana esté en plena crisis organizativa y económica.

Obviamente, la crisis está también en el resto de la Unión Europea, pero las universidades que más frecuento -las españolas y las alemanas- están insertas en un contexto estatal dirigido por un proyecto político. Por ello, en los recortes también crueles inferidos a las universidades alemanas se reconoce un proyecto general (sobre el cual se puede estar o no de acuerdo: pero al menos se sabe de qué se está discutiendo). Las universidades españolas no navegan por aguas tranquilas, pero ya desde hace años han superado a las universidades italianas, como escribí en el “Corriere della Sera” corrigiendo a un incauto chovinista italiano.

Por el contrario, en Italia, a veces tengo la sensación de que desde hace años alguien ha encerrado en una habitación del Ministerio de Roma a pedagogos enloquecidos, los cuales, de tanto en tanto, logran hacer llegar a la mesa del ministro la propuesta de modificar una realidad de la que ya no guardan memoria; propuesta burocráticamente aprobada en un clima de desinterés general. No exagero: la circular del 23 de mayo de 2005 sobre el "recorrido en Y" en las Facultades de Derecho llegó a las Facultades en junio, cuando los cursos habían terminado; pero para su aplicación se indica una fecha "apoyada por la administración que suscribe": "la del inicio del próximo año académico 2005-2006. Por ello, quitadas las vacaciones de verano, el plan de estudios de las Facultades de Derecho tendría que volver a redactarse en dos meses.

Aparte de estos aspectos à la Ionesco, el confuso proyecto neoliberal proclamado por el partido-empresa de un empresario perennemente bajo proceso tiene en la universidad efectos tan precisos como desastrosos. Se favorece a las escuelas privadas (que, en Italia, son preponderantemente confesionales) y a las universidades privadas. A las públicas se les pide que encuentren fondos en el mercado: por tanto, las Facultades científicas tienen que abandonar la investigación básica en favor de la aplicada, mientras que las Facultades de Humanidades tienen que apuntar hacia la cualificación profesional inmediatamente vendible. En las Facultades de Derecho, por lo tanto, ¿para qué perder el tiempo (y sobre todo, el dinero) con la filosofía del Derecho y disciplinas semejantes?

Esta tendencia a abolir las materias teóricas e históricas se encuentra en toda la Unión Europea. En Alemania se han abolido no sólo algunas cátedras de filosofía del Derecho, sino Facultades enteras. Pero Alemania 
vive, además de la crisis económica, también la reunificación y esta última había creado algunas duplicaciones inevitables. Además, el hecho de que los docentes alemanes enseñen dos materias permite reducir las materias histórico-teóricas sin dar demasiado en el ojo. Por ejemplo, el mismo docente enseña frecuentemente filosofía del Derecho y Derecho penal, o bien historia del Derecho alemán y Derecho civil: basta con aumentar las horas de Derecho privado para provocar la atrofia o la casi desaparición de la materia teórica.

La reforma “de Bolonia” respondía a una necesidad comunitaria, porque la libre circulación de los profesionales exige que estos tengan una preparación en cierta medida similar. La primera deformación de la reforma llegó con el martillazo de la crisis económica: precisamente en el momento en el que se necesitaba aumentar los fondos y los docentes, se ha tenido por el contrario que reducir ambos. Pero quizás esté llegando un nuevo martillazo. Habrá en efecto que ver si la crisis del espíritu europeo, sucedida con el referendum negativo en Francia y en Holanda sobre el tratado constitucional, no restituirá la fuerza a los corporativismos profesionales y, por tanto, no ralentizará también el modelo boloñés de europeización de las universidades. Veamos por qué.

En Italia, el modelo del "trienio más bienio", por ejemplo, no se ha adoptado nunca en las Facultades d Medicina. Además, existen poderosos colegios profesionales, entre ellos el de los abogados, que tiene su origen en las corporaciones fascistas y que defienden tomas de posición precisas: un abogado alemán no puede ejercer su profesión en Italia sin haber superado el examen italiano y sin haberse inscrito en el registro profesional italiano. Durante años la Unión Europea pidió abolir estos colegios profesionales que, sin embargo, hasta ahora han resistido victoriosamente. En particular, el colegio de abogados siempre ha criticado el modelo boloñés del "trienio más bienio”, prefiriendo a éste el viejo ordenamiento. Estas resistencias a la modernización de la universidad se volverán probablemente más fuertes con el debilitamiento actual del espíritu comunitario europeo.

Con el desbaratamiento de la nación, también mi espíritu crítico y mi identidad ideológica se han puesto en naftalina. Frente a la "reforma de Bolonia” y, hoy, frente al "recorrido en Y”, no oso ya ni siquiera emitir un murmullo de desaprobación contra los termitas neoliberales que corroen todo el edificio estatal y, por tanto, también la universidad. Ahora asisto al sucederse de las propuestas de los pirotécnicos pedagogos romanos con el pragmatismo desencantado de aquel comendador milanés que en 1914 -ante un grupo de exaltados que, en la Plaza de la Scala, le exigían que tomase opción: ¿’Quiere la paz o la guerra?”- respondía: “Me va bien la una o la otra, con tal de que sea una cosa bien hecha”. 
M.A.: Volvamos a la filosofía del Derecho. Tu has mostrado desde siempre un gran interés por Kelsen; has traducido algunas de sus obras capitales al italiano y has escrito también diversos trabajos de "kelsenianismo". ¿Cómo ves hoy la figura de Kelsen? ¿Ha sido realmente el mayor jurista del siglo XX? ¿Cómo ha influido en tu manera de entender la filosofía del Derecho y el Derecho? ¿Se puede -se debe- hoy ser kelseniano en teoría del Derecho? ¿En qué aspectos (si o no)?

M.L.: En la revista "Sistema” he recordado que Bobbio, “con un gesto de confianza que aún hoy me sorprende, en 1959 me confió la traducción de la segunda edición de la Teoría pura del Derecho": Hans Kelsen se convirtió así en un autor presente durante toda mi vida. Sin embargo no es por esta razón sentimental por la que sigo estando convencido de que Kelsen ha sido el mayor jurista del siglo XX. En el plano teórico, aunque no comparto del todo su teoría del Derecho, estimo que ella es una de las explicaciones más claras y eficaces del funcionamiento del Derecho en los Estados europeos industrializados. En el plano práctico, considero que Kelsen es un campeón de la democracia social-liberal precisamente en los años en la que era atacada más violentamente, es decir, en los años en que defenderla no sólo era incómodo, sino también peligroso. El triple exilio a Colonia, a Ginebra y a los Estados Unidos demuestra que su relativismo teórico no le impedía adoptar elecciones rigurosas en el campo político. El hecho de que hoy hasta la izquierda se haya medusée por un jurista luciferino y oportunista como Carl Schmitt (y que tienda a olvidar a su antagonista Kelsen) es un signo de los tiempos: un signo del oscuro alborear de este siglo XXI, cuyo exordio no muestra ciertamente una fuerte vocación por la legalidad.

Dicho esto, querría precisar que soy un kelsenólogo en el mayor grado, pero no ciertamente un kelsenólatra. De Kelsen aprecio mucho, pero no todo; y lo que aprecio lo inserto en el mosaico de mi eclecticismo metodológico. En la lectio doctoralis de Hannover -titulada Derecho turbulento. Nuevos paradigmas en las relaciones entre los Derechos nacionales y las normativas supraestatales, que aparecerá en la "Rivista Internazionale di Filosofia del Diritto”- he tratado de exponer en síntesis mi posición que aquí trataré de sintetizar aún más. Parto del axioma de que se acepte la doctrina que explique la mayor parte posible de los elementos que componen su objeto. La teoría pura del Derecho explica bien la dinámica del Derecho en el mundo industrial y democrático, que era justamente el mundo preferido por Kelsen: es una teoría general del Derecho europeo continental del siglo XIX-XX, es decir -en el fondo- una teoría menos general de lo que afirma ser. De hecho, para poder aplicarla a un cierto ordenamiento jurídico, es indispensable que este último opere en un contexto parlamentario, con la 
división clásica de poderes, con el poder judicial subdividido en diversos grados, etc.

Precisamente, de la constatación de que esta teoría (junto con otras) era una "teoría no muy general del Derecho" nació mi deseo de construir una “teoría verdaderamente general del Derecho”. Comencé pues a examinar algunos Derechos extraeuropeos. Esa serie de estudios aparentemente extravagantes confluyó en 1978 en el libro Grandi sistemi giuridici, del que estoy preparando la cuarta edición. El resultado al que llegué fue que una visión verdaderamente general del Derecho no se presta a ser encerrada en una única y homogénea teoría verdaderamente general del Derecho. Pero volvamos a Kelsen.

La curva de la fuerza explicativa de la teoría pura del Derecho cae bruscamente si se examinan los ordenamientos jurídicos de los Estados no industrializados o extraeuropeos: por ejemplo, los consuetudinarios del mundo arcaico o primitivo, o los regidos por un pluralismo jurídico como muchos Estados islámicos. En la lectio doctoralis de Hannover afirmaba además que:

“el riguroso positivismo legislativo no explica tampoco el Derecho postindustrial que parece consolidarse en nuestro tiempo: es decir, no explica el pluralismo jurídico. Ahora, también en Europa, en nuestras sociedades que se han vuelto multiculturales, se tiende a admitir la coexistencia de una pluralidad de ordenemientos normativos: por ejemplo, en la Italia católica, los tribunales no pueden intervenir contra la poligamia islámica, si está reconocida de manera regular en los países de origen. En algunos casos, el pluralismo jurídico genera directamente un pluralismo judicial. En Colombia, más de una vez el Tribunal Constitucional ha reconocido como válida la condena de un indígena establecida por un tribunal tribal según sus reglas consuetudinarias y ha impedido que la misma persona fuese juzgada por ese mismo delito por un tribunal estatal con base en los códigos en vigor. El riguroso positivismo legislativo no aceptaría nunca esta aplicación del civilizadísimo principio ne bis in idem"

Puesto que en la sociedad post-industrial continúan existiendo también estructuras sociales heredadas de la sociedad industrial, en el Derecho de la sociedad post-industrial conservan su validez algunas explicaciones que el positivismo jurídico había ya formulado para el Derecho de la sociedad industrial: no es necesario arrojar al mar a Kelsen sólo porque se elija una teoría jurídico-antropológica para explicar ciertas situaciones en Latinoamérica o en el Sudesde asiático. Simplemente, la doctrina jurídico-antropológica explica mejor el ordenamiento en el que conviven Derechos de origen europeo y Derechos consuetudinarios, mientras que la doctrina iuspositivista explica mejor el ordenamiento de una sociedad europea occidental. En 
suma, para mí, toda teoría, y por tanto también la teoría pura del Derecho, es un modelo explicativo, no una fe: por tanto, es lícito recurrir a varias teorías, mientras que se debe creer en una sola fe (si bien es aconsejable no ser demasiado rígidos ni siquiera en la fe: los japoneses, en general, tienen dos, el sintoismo para el más acá y el budismo para el más allá).

Además, en los tiempos de Kelsen la formación de estructuras supranacionales no era relevante de la manera en que lo es hoy. En todos los continentes coexisten hoy tres ordenamientos: el nacional, el supranacional y el internacional. La idea central de la teoría pura del Derecho consistía en reconducir cada nivel de la pirámide normativa a un único principio, la norma fundamental. Por eso, Kelsen colocaba al Derecho internacional inmediatamente por debajo de la norma fundamental, pero por encima de la Constitución nacional. Esta elección teórica contenía un claro mensaje democrático: en un ordenamiento estatal, sólo la Constitución y las leyes conformes con el Derecho internacional podían ser consideradas válidas. Es difícil estar de acuerdo, hoy, con la norma fundamental; pero también es difícil negar el coraje político ínsito en esta afirmación de Kelsen, en los años en los que se derrumbaba el mito de la Sociedad de las Naciones y los tratados internacionales eran escarnecidos como "trozos de papel”.

Hoy, situar también al Derecho comunitario europeo en aquella única pirámide normativa crea no pocas dificultades. Pero, por ahora, el problema del tercer nivel jurídico no ha sido resuelto ni por Kelsen ni por otros: es aún objeto de debate entre quienes estudian el Derecho constitucional de múltiples niveles. En este debate, Kelsen conserva un puesto de relieve, pues es necesario hacer frente a sus afirmaciones, sea para llegar a un consenso o a un disenso.

\section{M.A.: ¿Y cómo ha influido entonces Kelsen en tu propia obra?}

M.L.: Independientemente del puesto en el que se coloque a Kelsen en el Panteón de los juristas del siglo XX, está claro que, para mí, en el plano personal, traducir su obra más importante fue una experiencia altamente formativa. Escribía en "Sistema”: “Trabajar con Bobbio sobre Kelsen: iprueben a imaginar qué podría significar para un buen estudiante traducir a un autor meticuloso como Kelsen bajo la supervisión de un docente riguroso como Bobbio, para el cual la claridad de la exposición era un imperativo categórico! Esta necesidad de claridad ha seguido siendo, hasta hoy, un tormento para mí y, me temo, también para los que trabajan conmigo”.

En consecuencia, en el mosaico de mi eclecticismo metodológico ha entrado muy poco de Niklas Luhmann, aunque él se proponga explicar una sociedad más próxima a nosotros que la de Kelsen. Ese proceder per obscura ad obscuriora me es extraño, aún cuando a Luhmann me une una raíz 
común, puesto que en los años sesenta Luhmann fue, como yo, un pionero de la "iuscibernética". Al Luhmann anterior al "cambio de paradigma” de 1984 -esto es, al jurista Luhmann estudioso de la administración pública y del sistema cibernético- he dedicado todo un capítulo en el tercer volumen de mi libro Sistema e struttura nel diritto. Del lenguaje de la cibernética, Luhmann tomó (también a través de la mediación de Parsons) muchos elementos de su lenguaje autopoiético: pero el punto de oposición con los amigos luhmanianos está precisamente en el hecho de que Luhmann, en mi opinión, recibió de la cibernética más la terminología que los métodos y los conceptos. Después, nuestros caminos culturales se dividieron: en Luhmann la cibernética se vuelve cada vez más abstracta y se disuelve en la sideral teoría general de los sistemas, mientras que yo descendí del cielo de la cibernética a la sala de máquinas de la informática jurídica.

Pero si volvemos a los viejos maestros, a los que he mencionado al responder a la primera pregunta, encontramos inmediatamente los anticuerpos que acompañaban al inevitable entusiasmo juvenil con el que me aproximaba, más bien me sumergía, en la teoría pura del Derecho. Alessandro Passerin d’ Entrèves me reveló el lado laicamente iusnaturalista de Kelsen (en los aburridísimos años cincuenta el iusnaturalismo era exclusivamente católico y lo miraba con desconfianza también durante la década siguiente). Bobbio me enseñó a analizar la teoría pura del Derecho y a captar las contradicciones internas (a las que yo llamaba los "sobresaltos de humanidad" en Kelsen, cuando éste, en lugar de forzar la realidad para adaptarla a su teoría, adaptaba su teoría a la realidad a costa de resquebrajar la coherencia metodológica).

La traducción de la obra de Kelsen no se publicó hasta 1966, a causa de los retrasos editoriales ligados a la botadura de la nueva colección científica a la que estaba destinada. Pero la secuencia de mis intereses sucesivos tendría que demostrar que no me había concentrado solamente en Kelsen: en 1969 traducía Los conceptos jurídicos fundamentales de Wesley Newcomb Hohfeld; en 1970, Estructuralismo y ciencias humanas, de Raymon Boudon; y en 1972, El fin en el Derecho, de Rudolf Jhering. Este último fue sin duda el autor clásico que, junto a Kelsen, influyó en mayor medida sobre mi visión del Derecho; por ello, merece quizás la pena decir dos palabras sobre su presencia en mi actividad científica.

Comencé a traducir a Ihering después de haber publicado la traducción de Kelsen. En realidad, habría tenido que pasar el fatídico 1968 en París para iniciar el doctorado de troisième cycle con Raymond Polin. Llegué allí en marzo; en mayo, la Sorbona cerró sus puertas; en junio, la beca de estudios italiana se suspendió; en el verano tuve por ello que volver a Italia y, desde ese momento, me concentré en mis autores alemanes y en la informática. 
Para mí, nacido entre viñedos, el 1968 fue el “tiempo del mosto”, es decir, la estación mágica en la que se pone a fermentar en la cuba lo que se transformará en vino de añada. De hecho, a pesar de los contratiempos académicos y burocráticos, en mi caótico 1968 inicié la fermentación de numerosos proyectos, destinados a alcanzar el grado justo de maduración en los años sucesivos. Ante todo, adoptaron la forma de publicación los dos nuevos intereses que habrían debido desarrollarse en los años sucesivos. De hecho, en 1968 publiqué tanto la primera bibliografía completa (en la medida en que puede serlo una bibliografía) de Jhering, como el primer artículo sobre la “iuscibernética”. Pero en 1968 publiqué también, para mi habilitación, el primer volumen de Sistema e struttura nel diritto que iba Dalle origini ala Scuola Storica, llevándome así hasta el umbral de Kelsen (umbral que me llevaría un poco de tiempo atravesar, puesto que los tres volúmenes sobre la noción de sistema aparecieron más de 30 años después, en 2002). Siempre en 1968, participé en el congreso de Göttingen del ciento cincuenta aniversario del nacimiento de Jhering: allí se inició mi larga amistad con el sueco Sten Gagnér, estudioso de rara generosidad que me animó a publicar los tres volúmenes de la correspondencia de Jhering en su cátedra de Historia del Derecho, en Munich, en Baviera.

De Jhering me fascinaba el entourage pandectístico de sus primeras obras y su posterior ruptura metodológica con el pasado, para acompasarse con la modernidad de Europa en la segunda mitad del diecinueve. Me fascinaba también la multitud heterogénea y efervescente de sus seguidores: desde la Jurisprudencia de intereses y el movimiento del Derecho libre hasta los Critical Legal Studies norteamericanos y el Derecho alternativo de la Europa continental y de América latina.

En suma, mi pasión por el rigor conceptual y terminológico de Kelsen estaba, y está, atemperada por numerosas aportaciones de estilo bien diverso. Con todo, mi interes por Kelsen no disminuyó nunca. En 1975 vio la luz, como volumen autónomo, Il problema della giustizia, que en la edición alemana era el apéndice de la Reine Rechtslehre. Publiqué varios ensayos de análisis de la doctrina pura del Derecho; en 1981 los recogí en un volumen (Forma e realtà in Kelsen); en 1985 revisé la traducción de la obra póstuma Teoria generale delle norme. En fin, en 1998, Bobbio me confió la tarea de recuperar y publicar los manuscritos del debate entre Hans Kelsen y Umberto Campagnolo (un viejo amigo suyo y compañero de batallas civiles), que tuvo lugar en los años treinta durante su exilio en Suiza. Tuve incluso el placer de poder entregarle, en 1999, la edición bilingüe de aquel debate (Diritto internazionale e Stato sovrano) y, en 2000, la traducción publicada en Brasil de ese volumen. 
En conclusión, Kelsen no me abandona, ni yo le abandono a él: precisamente por esto, he querido dedicar la lectio doctoralis de Hannover a la relación entre su teoría y el mundo moderno, que tiene su símbolo en la confrontación-enfrentamiento entre la imagen de la pirámide y la de la red.

M.A.: ¿Se puede entonces -o se debe- ser hoy kelseniano en la teoría del Derecho?

M.L.: Lo que he estado diciendo debería responder ya implícitamente a esa cuestión. No creo que "se deba” aceptar la teoría pura del Derecho como una estructura monolítica: esta estaticidad metodológica se la dejamos a los kelsenianos. "Se puede” -en mi opinión- ser "kelseniano” en cierta medida, esto es, aceptando aquellas partes de su obra que aún hoy tienen relevancia. Por ejemplo, la estructura por gradas (la pirámide) explica bien la estructura de un ordenamiento moderno, aunque no se acepte su clausura hacia lo alto con una norma fundamental: se puede seguir al jurista Kelsen sin tener que transformarse también en un filósofo neokantiano. Ya el mismo Kelsen, de joven, se daba cuenta de que quien indaga en la fuente última de la validez del Derecho resulta deslumbrado por "los ojos rasgados de la Gorgona del poder".

Además, la claridad expositiva de los textos kelsenianos los hace particularmente aptos para la enseñanza, incluso como base inicial para una discusión que siga después líneas no kelsenianas: piénsese en libros cortos pero densos como Qué es justicia y la primera edición de la Teoría pura del Derecho, para limitarme únicamente a textos jurídicos.

Pero no debemos olvidar que Hans Kelsen no fue únicamente un filósofo del Derecho: y aquí me permito traspasar el límite de la cuestión que se refiere sólo a la iusfilosofía kelseniana. Kelsen fue también un iuspublicista al que debemos una contribución decisiva a la Constitución austríaca de 1922 y la fundación del Tribunal Constitucional austríaco. De aquí a la politología el trecho es corto: piénsese en sus escritos en favor de la democracia y en los de crítica del comunismo. Después del primer exilio, en 1930, llegó a ser también un internacionalista de fama mundial.

En su bibliografía, los escritos iusfilosóficos ocupan, en cuanto al número, sólo el tercer puesto y, a mi juicio, tienen un origen ocasional. De hecho, Kelsen escribió la primera edición de la Teoría pura del Derecho después de la toma del poder por parte de los nacionalsocialistas en Alemania, cuando ya sentía como inevitable su segundo exilio y quería, por tanto, darse a conocer con una obra que tuviese un valor universal, en cuanto no ligada a un Derecho nacional. Sin este impulso externo, la teoría de origen neokantiano, que estaba ya en la base de sus trabajos de Derecho público e internacional, quizás no hubiese encontrado nunca una formulación autóno- 
ma. En el fondo, la segunda edición de la Teoría pura del Derecho, de 1960, es el desarrollo de los temas de la primera edición de 1934, mientras que sus numerosos artículos iusfilosóficos son puestas a punto, profundizaciones o revisiones, de problemas concretos ya in nuce en la teoría concentrada en la summula de 1934.

Querría concluir con una invitación a la "kelsenología”. Precisamente, la publicación del inédito sobre el Derecho internacional, que muestra a Kelsen polemizando con Campagnolo, me ha hecho constatar hasta qué punto puede ser útil una reconstrucción histórica y filológica del legado publicado e inédito de Kelsen. Este jurista, agudo y de indiscutida honestidad intelectual, fue un testigo directo y con frecuencia privilegiado de años tormentosos, que se reflejan en sus obras en una medida aún por determinar. Muchas de sus publicaciones han sido traducidas al italiano: en esta vía, por ejemplo, Agostino Carrino ha recogido frutos copiosos. La experiencia filológica madurada con la correspondencia de Jhering me induciría a recorrer el mismo camino con los inéditos kelsenianos: pero las cosas son menos simples de lo que pudiera parecer.

En efecto, después de la muerte de Kelsen en 1973, su archivo se ha trasladado de los Estados Unidos a Viena, en donde se ha creado la fundación federal “Hans-Kelsen-Institut”, para favorecer la conservación de los documentos y la difusión del pensamiento kelseniano. Pero, inexplicablemente, el archivo es inaccesible desde hace años: por tanto, se puede hoy ser kelseniano, pero no es fácil ser "kelsenólogo".

M.A.: En las anteriores preguntas y contestaciones han surgido, inevitablemente, diversos autores (Bobbio, Kelsen, Jhering) y diversas corrientes iusfilosóficas. ¿Cuál es hoy tu posición, como teórico o filósofo del Derecho, respecto de estas últimas? ¿Qué piensas, en particular, sobre las tres grandes direcciones que hoy parecen ser las más compartidas entre los filósofos del Derecho: el positivismo jurídico (normativista o realista), el iusnaturalismo y las teorías críticas del Derecho?

M.L.: ¡Temible cuestión! Ahora tendría que precisar cuál es mi metodología, mi Methodenlehre in nuce, lo que requeriría un fresco de proporciones miguelangélicas, pero aquí tendré que limitarme a pocas pinceladas de impresionista menor. Por fortuna, la entrevista es un género convivencial. Las respuestas tienen psicológicamente una naturaleza "hablada”, aunque de hecho son por escrito, y permiten por tanto una cierta dosis de improvisación y también de imprecisión. Me excuso con el lector; pero una respuesta mínimamente articulada a esta temible cuestión se transformaría en un manual. 
Hasta ahora no he escrito un manual o un tratado de filosofía del Derecho, porque no me siento vinculado a un método. También desde el punto de vista metodológico soy, así pues, un perro sin collar, un lobo solitario: no por casualidad, cuando contestaba a la primera pregunta, ironizaba sobre mi moderado anarquismo. Esto no significa, sin embargo, que cuando emprendo una investigación no me plantee la cuestión de cómo desarrollarla lo mejor posible, esto es, de cómo describir, explicar y valorar de la manera más exhaustiva posible el objeto del que me ocupo. Simplemente, no creo que exista un único método cuyas formulitas "ben studiate e calibrate” sean de ayuda "per spiegar nel loro intrìco / dal buon Dio fino al lombrico" (como escribía Umberto Eco, si recuerdo bien, a propósito de la Summa de Santo Tomás, en su juvenil e inencontrable librito de poemas Filosofi in libertà).

La realidad presenta infinitas facetas, y cada una puede ser examinada desde diversos puntos de vista. Estoy convencido de que es imposible que un único instrumento sea adecuado para cada faceta y para cada punto de vista. Un único instrumento sólo es adecuado si se limita mucho el campo de observación; pero de este modo se ponen también límites a la propia curiosidad y a la propia libertad, y estos límites son precisamente los que siempre he rechazado con impaciencia. Mejor la acusación de eclecticismo que la de monotematismo. Mejor vérselas con cientos de métodos en torno a cientos de formas de ver la realidad, que afinar un único método que explica un único fragmento de la realidad. Las dos aproximaciones son científicamente aceptables, no hay ninguna razón determinante por la que uno deba ser preferido al otro. Si he preferido el eclecticismo, y no el monotematismo, es porque desconfío del fontanero que llega con un solo utensilio, mientras que me da seguridad el que llega con una caja de instrumentos.

Es verdad que el observador modifica el objeto observado: la tribu primitiva deja de serlo en el mismo momento en que el primer antropólogo entra en contacto con ella. Pero también es cierto que el objeto de la investigación "habla” a quien lo estudia y termina por dirigirle la investigación. Por lo tanto, se puede iniciar una investigación inspirándose rigurosamente en un único método, para después descubrir el camino haciendo -y aquí está verdaderamente el "descubrimiento"- que ese objeto sea contemplado de manera distinta y que bajo este regard indiscret despliegue una mayor riqueza de contenidos. No creo, en suma, que se esté completamente libre de condicionamientos en la elección de un método de investigación y, por tanto, en los resultados a los que se llega. El pensador norteamericano Valdo Emerson comparaba al filósofo con el patinador: en parte va en la dirección elegida, y en parte va a donde le llevan los patines. Tobias Barreto -el germanófilo brasileño al que dediqué el volumen Un giurista tropicale- retoma esta imagen, precisando que le era difícil, en Brasil, imaginar a un patinador 
sobre el hielo, pero que comprendía bien la metáfora si, en lugar de en los patines, pensaba en una canoa: también el canoista va en parte a donde ha decidido ir, pero en parte a donde lo lleva la corriente.

Esta introducción quiere precisar que yo sigo un método, pero sin volverme su prisionero. Mi método podría ser definido -para usar los términos de la pregunta a la que estoy contestando- como un positivismo realista: volvemos así a aquel "realismo modesto y caritativamente ecléctico" al que me refería en la primera pregunta. Volviendo al tema, me limitaré a unas pocas indicaciones sobre algunos de los problemas fundamentales de la filosofía del Derecho, tratándolos, sin embargo, con una concisión insatisfactoria: sin embargo, como decía poco antes, si quisiera afrontarlos como merecerían, tendría que escribir el manual de filosofía del Derecho que nunca he escrito.

Para los juristas, tanto "positivismo jurídico" como "realismo jurídico" son términos con múltiples significados que, sin embargo, tienen un núcleo común. La ambigüedad de las definiciones corresponde a la flexibilidad del método. Por ejemplo, cuando me ocupo de problemas de las sociedades occidentales contemporáneas, practico un positivismo jurídico bastante estricto: para mí, es Derecho sólo el Derecho puesto -positum- del Estado, pero no otro sistema normativo aplicado en ciertos subsistemas de la sociedad. Las reglas de conducta social seguidas por los gitanos, por los socios del Rotary Club, por los Testigos de Jehová o por los que frecuentan la Biblioteca Nacional son para mí normas, pero no normas jurídicas: las estudio, por lo tanto, según un método también realista (antropológico o sociológico) y no según un método únicamente normativista. Mi positivismo se diluye aún más cuando, aún permaneciendo en el ámbito de los Derechos codificados, salgo de Europa y me ocupo de las sentencias alternativas que se refieren a los "Sin Tierra" del Brasil o a las sentencias del Tribunal Constitucional colombiano que reconocen el Derecho indígena como sistema normativo paralelo al Derecho estatal. Mi positivismo se disuelve casi del todo cuando me enfrento con el pluralismo judicial del Togo o el ordenamiento sociojurídico de los cheyennes.

¿Pero puede un positivismo jurídico que sea “modesto" (esto es, que no pretenda explicar todos los fenómenos jurídicos) y “caritativamente ecléctico" (es decir, abierto a las aportaciones de otras disciplinas, si estas se muestran heurísticamente más fructíferas) seguir siendo definido como positivismo jurídico? Yo creo que sí, al menos en el sentido de que participa de un elemento común a los distintos positivismos: la oposición al iusnaturalismo. Obviamente, también éste se concibe de mil maneras. Aquí me limito a subrayar el elemento conceptual que diferencia al positivismo 
jurídico del iusnaturalismo: para el positivismo jurídico, el Derecho es un producto humano.

Obviamente, de esta posición se deriva una separación conceptual entre el Derecho y la moral que, sin embargo, no me parece que implique también una división metodológica entre los dos campos. Las normas del Derecho positivo europeo incorporan valores morales (o concepciones de la justicia) en todos los niveles: desde los principios constitucionales hasta las normas penales sobre el hurto, desde las normas civiles sobre la propiedad hasta las normas procesales sobre el derecho de defensa del imputado, todo legislador persigue el "bien común” o, al menos, dice o cree perseguirlo. Traduce por tanto en normas jurídicas un valor metajurídico, y un positivismo que quiera explicar lo que sucede en el mundo del Derecho debe tenerlo en cuenta. Baste aquí con evocar como ejemplo el debate sobre la relación entre los derechos humanos (como valores metajurídicos) y los derechos fundamentales del ciudadano (como moral positivizada en normas jurídicas). Cuando se habla de un conflicto entre norma jurídica y moral ello se refiere, en realidad, a un conflicto interno a la moral, esto es, al conflicto entre la concepción originaria del legislador y la del intérprete. Y así llegamos al problema de la interpretación.

En los Derechos occidentales -es decir, en los de Europa Continental y en el common law, donde quiera que se hayan adoptado- el Derecho es establecido por el Estado tanto en el nivel general, con las leyes, cuanto en el nivel individual, con las sentencias. Una teoría del Derecho que quiera abarcar todo el ordenamiento debe por tanto tener en cuenta también la interpretación que se da a una cierta norma. También por esta vía entra la moral en el Derecho. Un ejemplo clásico es el código civil alemán, que está en vigor en el imperio guillermino, en la república socialista de Weimar, en el Tercer Reich, en la Alemania del Oeste liberal-democrática y en la Alemania oriental comunista: como señalaba el sociólogo Lawrence Friedman, evidentemente la vida del Derecho se desarrollaba fuera de este código. Un ejemplo más reciente es el artículo de la Constitución brasileña de 1988 que establece el derecho a "una vida digna” para todo ciudadano. Esta norma constitucional se ha convertido en el elemento de conexión entre una cierta moral social y la aplicación de un Derecho positivo inspirado, por el contrario, por una visión distinta de la sociedad: en concreto, los jueces alternativistas brasileños interpretan "creativamente” las normas del Estatuto de la Tierra, emanado bajo la dictadura militar, a la luz de la nueva constitución democrática.

Creo, en suma, que un positivismo jurídico no puede dejar de tener en cuenta también la dimensión política (y, más en general, ética) ínsita en las normas jurídicas cristalizadas en las leyes y en los códigos. En este punto es donde se plantea el problema de la objetividad de la investigación: tanto el 
estudioso como la norma estudiada incorporan valores, y los valores aceptados por el primero no están necesariamente en armonía con los de la segunda. Para explicar a fondo la realidad jurídica es necesario, por ello, analizar el origen valorativo (es decir, el fundamento político) de la norma a examen, pero hay también que ser consciente de que el observador mismo es portador de valores que influyen tanto en el análisis como en la valoración de aquella norma. Se necesita por ello exigir del estudioso no tanto una inalcanzable avaloración, cuanto una consciente honestidad intelectual.

Al estudiar a los marginados, por ejemplo, las implicaciones emotivas corren el riesgo de influir en el análisis de los hechos y en la valoración de las normas jurídicas. Una clara (y rara) toma de posición metodológica a este respecto se encuentra en el volumen sobre la situación actual de los gitanos en Europa oriental, publicado en 2002 por Zoltan Barany, de la Universidad de Texas. Barany advierte: "Dadas las condiciones verdaderamente lastimosas en las que vive la mayoría de los gitanos, quien los estudia puede fácilmente perder su objetividad y convertirse de facto en un activista gitano", en el sentido de "excederse al enfatizar las ofensas realmente padecidas por los gitanos", ignorando sin embargo al mismo tiempo "las responsabilidades de los gitanos por su valoración social y minimizando los esfuerzos del Estado y de las organizaciones para prestarles asistencia”. La actitud científica consiste en no caer en el compromiso emotivo (muy laudable, pero para otros fines) y eventualmente en formular propuestas que el "activista gitano” no tomaría tampoco en consideración: si quieren salir de la situación de inferioridad en la que se encuentran, concluye Barany, los gitanos deben también "realizar un gran esfuerzo por reducir su marginalidad: esfuerzo que alguna vez puede requerir la revisión de antiguas tradiciones romaníes”. Una actitud análoga de distanciamiento consciente es, a mi juicio, indispensable también para el teórico del Derecho.

M.A.: De entre tu amplísima producción, ¿hay alguna obra que destacarías especialmente? ¿Por qué? ¿Cabe hablar de fases o de etapas en tu pensamiento? ¿Cuáles serían? ¿Cuáles consideras que son tus principales aportaciones a la teoría y a la filosofía del Derecho?

M.L.: Como me ocurre siempre ante un formulario de autovaloración, oscilo entre los dos polos del narcisismo y la autolesión, a la búsqueda de un juicio que no se si coincidirá con el de los lectores.

He escrito mucho porque soy hombre de poca memoria: tengo necesidad de fijar en el papel los documentos que encuentro y los pensamientos que rumio porque, de otra manera, los olvido. Si los olvidara, no sería un gran daño para la humanidad, pero a mí me disgustaría porque, como todo autor, pienso que son útiles para la comunidad científica: sin este componente 
narcisista no se escribirían libros. A ello se añade el hecho de que elijo los temas de investigación en base a mi interés y a mi curiosidad, incluso a costa de hacer frente a las críticas de la academia. Y, puesto que no se trata de curiosidades pasajeras, sino de inquietudes más profundas, tiendo a no abandonar nunca los temas afrontados. El resultado es una progresiva dilatación de la esfera de mis intereses y, por tanto, de mis escritos: se añaden siempre nuevos temas, pero nunca se pierden los viejos. A causa de este entrelazamiento de intereses, mis tiempos de realización son con frecuencia larguísimos (baste pensar en la investigación de treinta años sobre la noción de sistema en el Derecho, a la que volveré en seguida); es una lentitud debida no a la pereza, sino a la oclusión.

Es por ello difícil individualizar fases en el arco ya de cuarenta años de mi producción, porque ciertos temas prevalecen, después se atenúan porque otros ganan la delantera, después quizás desaparecen durante algún año y, finalmente, regresan. Entre tanto, he continuado recogiendo, para cada uno de ellos, libros y documentos que, al acabar por estar en mi biblioteca en un orden casual, adquieren una frondosidad amazónica de la que se alimentan los retornos sobre el mismo tema. No pienso tampoco en hacer un catálogo de mi biblioteca: la vida es breve, los libros son muchos, y yo prefiero leer los libros que no catalogo a catalogar los libros que no leo.

Teniendo en cuenta esta estratificación de intereses, indicaré cinco temas (más que fases) en torno a los cuales se condensan mis trabajos. Haré el elenco -por así decir- por fecha de nacimiento, esto es, según un orden aproximadamente cronológico porque cada uno de ellos se añade a los precedentes, pero sin sustituirlos. Los cinco temas son: Kelsen y el positivismo jurídico; Jhering (seguido de las corrientes antiformalistas), que culmina en los tres volúmenes de su correspondencia; la informática jurídica que culmina en los tres volúmenes del Corso; los grandes sistemas jurídicos europeos y extraeuropeos; y, finalmente, la noción de “sistema” en el Derecho, que culmina en los tres volúmenes sobre este tema. Otros temas -pero no filosófico-jurídicos y, por tanto, fuera del contexto de esta pregunta-son la política italiana y comunitaria, la historia de las máquinas de cálculo que Fosco Maraini llamaba mi “violon d’Ingrès”: la historia de los autómatas. Pero volvamos a los cinco temas iusfilosóficos y a la obra que, para cada uno de ellos, me parece hoy más relevante.

Sobre Kelsen y el positivismo jurídico (el primer tema del que me ocupé siendo todavía estudiante) resaltaré tres traducciones ${ }^{1}$ y la recopilación

\footnotetext{
${ }^{1}$ Hans Kelsen, La dottrina pura del diritto, Einaudi, Torino 1966, CIII-418 pp.; Hans Kelsen, Il problema della giustizia, Einaudi, Torino 1975, XXXIX-133 pp.; Hans Kelsen, Teoria generale delle norme, Einaudi, Torino 1985, LXV-471 pp.
} 
de mis estudios sobre Kelsen de $1981^{2}$. Naturalmente, mis investigaciones sobre Kelsen continuaron después de esa fecha: baste con recordar la publicación del inédito kelseniano sobre el Derecho internacional de 1999³.

Para Jhering y las corrientes antiformalistas es relevante, sobre todo, en italiano, la traducción de El fin en el Derecho ${ }^{4}$ y, en alemán, la edición en tres volúmenes de la correspondencia de Jhering con Gerber, Glaser y Unger $^{5}$, que ha sido definida, para este periodo de postguerra, como una de las mayores publicaciones de fuentes para la historia del Derecho alemán. A esta edición y a la amistad de Peter Landau -el historiador del Derecho de la Universidad de Munich en Baviera, sucesor del inolvidable Sten Gagnér- debo el premio Alexander von Humboldt.

En el ámbito de la informática jurídica considero que mi escrito más importante son los tres volúmenes del Corso di informatica giuridica ${ }^{6}$ de 1985-86. Marcaron la conclusión de muchos de mis estudios preparatorios y de experiencias prácticas innovadoras y, en Italia, dieron un fundamento orgánico a la disciplina. De mi interés por la privacy ya he hablado antes. En la informática surgen siempre nuevas posibilidades técnicas y, por ello, he renovado constantemente mis temas de investigación: en mis experimentos y en mis escritos, después de los bancos de datos on line y de la privacy, vinieron los sistemas expertos, los CD-ROM y, hoy, la edición electrónica, el teaching libraries y formas específicas de e-government. También aquí mi trabajo ha sido más valorado en el extranjero que en Italia: de hecho, debo el doctorado honoris causa a la Universidad de Hannover y a la amistad de Wolfgang Kilian que, desde hace dos décadas, dirige el Instituto para la Informática Jurídica.

Mi interés por los grandes sistemas jurídicos recibió impulsos precisos de mis viajes extraeuropeos, iniciados con el de Asia a finales de los años sesenta. Para no caer en el puro exotismo jurídico, evité estudiar aspectos extranjeros de Derechos extranjeros (eso pueden hacerlo mejor los propios

\footnotetext{
${ }^{2}$ Forma e realtà in Kelsen, Comunità, Milano 1981, 229 pp.

${ }^{3}$ Hans Kelsen-Umberto Campagnolo, Diritto internazionale e Stato sovrano, Giuffrè, Milano 1999, XI-402 pp.

${ }^{4}$ Rudolf von Jhering, Lo scopo nel diritto, Einaudi, Torino 1972, CIII-419 pp.

${ }^{5}$ Der Briefwechsel szwischen Jhering und Gerber, Verlag Rolf Gremer, Ebelsbach 1984, XXII-693 pp.; Studien zu Jhering und Gerber, Verlag Rolf Gremer, Ebelsbach 1984, XXIII-432 pp.; Der Briefwechsel mit Unger und Glaser, Aktiv Verlag, Ebelsbach 1996, XIII-337 pp. Estos volúmenes forman parte de la colección Abhandlungen zur rechtswissenschaftlichen Grundlagenforschung de la Universidad de Munich. Fueron anticipados por una traducción italiana (a revisar hoy a la luz del texto alemán): Carteggio Jhering-Gerber (1849-1872), Giuffrè, Milano 1977, LXVII-733 pp.

${ }^{6}$ Corso di informatica giuridica, Einaudi, Torino: Informatica per le scienze sociali, 1985, XXI-547 pp.; Il diritto privato dell'informatica, Einaudi, Torino 1986, IV-348 pp.
} 
extranjeros) y traté de concentrarme en la circulación de las ideas jurídicas europeas fuera de Europa. En 1978, un volumen completó y condensó estas experiencias ${ }^{7}$, también en la ola de la reforma que, pocos años antes, había transformado (pero sería más correcto decir: destruido) la universidad italiana.

Escribía, en efecto, en el prefacio a la traducción española de aquel volumen ${ }^{8}$ : "Este libro es el fruto tal vez feliz de un momento de la universidad italiana sin duda infeliz”. Sin embargo, continuaba, “enseñar en una atmósfera de este tipo produce desconsuelo", pero produce también "una serie de problemas prácticos que, desconsolado o no, hay que resolver”: mis estudiantes venían de las más heterogéneas escuelas secundarias y, además, tenían escasas nociones jurídicas (si eran estudiantes de ciencia política) o bien de historia y de política (si eran estudiantes de Derecho): “por ello decidí redactar un manual que les ofreciera un panorama del Derecho, supliendo así en cierta medida las carencias de su curriculum de estudios universitarios”. Pero al prepararme para ese trabajo de peonaje académico "me asaltó el viejo deseo [...] de escribir una teoría verdaderamente general del Derecho, es decir, una teoría que se fundara sobre todos los sistemas jurídicos”. Puesto que no podía "afrontar esa tarea grandiosa en una universidad inexistente", "la estructura definitiva del volumen tomó forma en un nevado febrero bávaro”, en la Bayerische Staatsbibliotek en la que trabajo desde hace más de treinta años y en la que me siento -como he escrito en un ímpetu de bibliotecofilia- "wie eine Maus in Parmesankäse”, como un ratón dentro de un queso parmesano.

En fin, las investigaciones sobre la noción de "sistema" en el Derecho me fueron confiadas por Bobbio en los años sesenta, pero sólo las completé con los tres volúmenes publicados después de $2000^{9}$, confirmando así mi constante fidelidad a los proyectos, pero no una gran rapidez en su realización. En el prefacio al primer volumen trataba de explicar así la génesis y el método de toda la investigación: "El presente libro no es ni el ininterrumpido trabajo de décadas, ni una reanudación después de una larga interrupción, sino una vía intermedia: aunque atraído por temas distintos del de sistema, he continuado ocupándome de él en una serie de investigaciones sectoriales que han preparado el segundo y el tercer volumen. Ya en el primer volu-

\footnotetext{
${ }^{7}$ I grandi sistemi giuridici. Introduzione ai diritti europei ed extraeuropei [tercera edición ampliada], Laterza, Roma-Bari 2000, XIX-550 pp.

${ }^{8}$ Los grandes sistemas jurídicos. Introducción al Derecho europeo y extranjero. Versión castellana de Alfonso Ruiz Miguel, Editorial Debate, Madrid 1981, p. 12 y s.

${ }^{9}$ Sistema e struttura nel diritto, Giuffrè, Milano 2002: Vol. 1: Dalle origini alla Scuola storica, XXIX-373 pp.; Vol. 2: Il Novecento, XVIII-311 pp.; Vol. 3: Dal Novecento alla postmodernità, XVIII-371 pp.
} 
men había indicado la línea de investigación que trataba de seguir en los siguientes: obviamente, en el curso de tres décadas me he apartado de ello, pero no demasiado, y el índice actual no está, pues, muy lejos del plan original $^{10}$. Pero la evolución del pensamiento sistemático en el Derecho no es tanto el tema para una monografía, cuanto una clave de lectura para afrontar toda la historia del pensamiento jurídico: y la vastedad impone elecciones. Contemplando la floresta de la ciencia, hay quien se ocupa de las hojas y no ve ya la vastedad del bosque, y hay quien se ocupa del bosque y no ve ya la variedad de las hojas. Yo trato, por el contrario, de seguir un sendero que, de árbol en árbol, atraviesa el bosque y, de cuando en cuando, me paro a mirar alguna hoja que me parece atractiva”. (vol I, p. XXI). Pero para el que es curioso, las "hojas atractivas" son infinitas y, así, en la preparación de la traducción española de los tres volúmenes, estoy pensando ya en una serie de profundizaciones.

Como se ve, mi aportación a la filosofía y a la teoría jurídicas se caracteriza por el predominio de la aproximación histórica respecto a la analítica. Si tuviera que sintetizar al máximo los puntos que me parecen centrales en mi trabajo, indicaría la historia del pensamiento jurídico (es decir, las traducciones de algunos textos clásicos, la publicación de inéditos, así como el análisis de algunos conceptos centrales en Kelsen, Jhering y Hohfeld) y la dimensión jurídica del actual multiculturalismo (es decir, los escritos sobre los grandes sistemas jurídicos y sobre la circulación de las ideas jurídicas europeas fuera de Europa). A ello añadiría -como aportación innovadora a la noción clásica de filosofía y teoría del Derecho- la aportación a la fundación y a la delimitación disciplinar de la informática jurídica y del Derecho de la informática, desde su inicial separación del tronco central de las disciplinas jurídicas hasta su institucionalización también universitaria. Hoy las agrupaciones ministeriales de las disciplinas (las que sirven para los concursos de cátedras) incluyen en el mismo grupo la filosofía del Derecho, la teoría del Derecho y la informática jurídica.

En estas décadas de estudio, siempre he visto mi presente como el momento en el que el pasado, sobre todo del XIX y del XX, entra en contacto con el futuro tecnológico. Nada de nuevo, en el fondo: ya Ovidio decía "laudamus veteres sed nostris utimur annis".

M.A.: Para terminar la entrevista, me gustaría hacerte dos preguntas: una mira hacia el pasado, y la otra hacia el futuro. Hacia el pasado.

10 "El proyecto de la investigación [entonces futura, hoy realizada (aunque a grandes líneas)] está delineado con juvenil imprudencia en la Introducción, en Losano, Sistema e struttura nel diritto (1968), pp. XXV-XXXI”. 
Imagina que dispusiéramos de una máquina del tiempo y que pudiéramos enviarte, digamos, al momento en que terminaste tus estudios de Derecho: ¿Volverías a ocuparte de lo mismo de lo que te has ocupado? ¿Habrías elegido seguir una carrera universitaria y, en concreto, en el ámbito de la filosofía del Derecho? Hacia el futuro: ¿Cuáles son tus proyectos de trabajo intelectual para los próximos años? Aunque resulte impertinente, o extraño, planteárselo a alguien tan prolífico como tu: ¿hay algún libro que habrías querido escribir y que (aún) no has escrito?

M.L.: La elección de la filosofía del Derecho fue una elección querida al principio con algunas inseguridades y, después, radicalizada por los acontecimientos. Como para el patinador de Emerson o el canoista de Barreto, había elegido la dirección, pero los azares de la vida se habían encargado después de determinar el itinerario concreto. Acosado entre el interés por las ideas y la pasión por la realidad, en el momento de la tesis de doctorado no había aún decidido con precisión la disciplina a la que dedicarme en el futuro: estaba dividido entre las grandes ideas políticas y su concreta aplicación social. De ello resultó una tesis híbrida de Derecho constitucional ( $\mathrm{La}$ concepción de la constitución en las democracias populares) dividida en dos volúmenes: el primero sobre la teoría del Derecho y del Estado en Marx y Engels (dirigida por Bobbio y publicada después en 1969) y el segundo, de análisis jurídico de esas constituciones. En 1962 me licencié en Derecho constitucional con el socialista Franco Pierandrei, con el cual habría tenido que continuar mi anfibia carrera académica.

Pero el destino decidió de otra manera: pocos días después de mi examen de licenciatura, Pierandrei murió de repente en las pistas de esquí en el Valle de Susa y yo me encontré “adéspotos”. Para ocupar la cátedra en Turín se llamó al óptimo constitucionalista Leopoldo Elia, democristiano destinado a una brillante carrera. La cátedra de Bobbio estaba ya llena. Puesto que en esos años las identidades ideológicas trazaban barreras netas, en la universidad no me quedaban muchas oportunidades.

Trabajé por ello fuera de la universidad. En 1963, entré en el despacho de estudios del Istituto Finanziario Industriale, la sociedad financiera de la familia Agnelli; desde 1964 pasé a la editorial Einaudi. Recuerdo con gratitud el año transcurrido en el grupo Fiat, porque tuvo un peso decisivo en mi formación: me permitió vivir desde dentro el capitalismo, corrigiendo algunos aspectos de mi radicalismo juvenil. Trataba con capitalistas que aprendí a apreciar por su preparación profesional y su disponibilidad humana: no eran ciertamente los hombres obesos que la revista soviética "Krokodil” representaba con frac y bombín, escribiendo debajo "kapitalist" para no dejar dudas al lector proletario. Si, por un lado, ese año reforzó mis 
convicciones reformistas, por otro lado, me hizo también conocer las inevitables disfunciones de la economía privada. Las encontraría luego, en los años posteriores, también en aquella anómala sociedad por aciones que era la Einaudi de sus años de oro: recuerdo a un Raffaele Mattioli, el banquero humanista de la Banca Commerciale Italiana, que salía desconsolado del despacho de Giulio Bollati diciendo: "La empresa está quebrada, la empresa está quebrada”; sin embargo, con razón, Ernesto Ferrero, al escribir sus recuerdos sobre estos años, los ha titulado Los mejores años de nuestra vida. Gracias a esta vacunación en el sector privado, en las décadas transcurridas en la universidad pública fui menos propenso a mitificar la economía privada, que era contemplada por muchos colegas como un inalcanzable modelo de perfección de eficiencia.

Paralelamente al trabajo en la empresa, continuaba estudiando -no sin desviaciones hacia el ámbito literario. Sin embargo, los años entre 1963 y 1966 me habrían llevado definitivamente fuera de la órbita universitaria si, en 1966, el Kelsen traducido años antes no hubiese sido finalmente publicado. En ese mismo año, con un inolvidable gesto de gran amistad, Amedeo G. Conte- que acababa de ser nombrado catedrático en Pavía- me nombró su ayudante voluntario en esa universidad. Entre tanto, fue a visitarme a Turín Renato Treves, que quería hablarme de la reedición del libro de Kelsen, traducido por él en 1934. Todavía lo veo en mi casa, cuando concluyó la conversación sobre nuestros proyectos kelsenianos con la pregunta: “¿Por qué no viene conmigo a la Universidad de Milán?”. Volvía así, gracias a Conte y a Treves, a la carrera del estudio. Pero fue una carrera anómala.

De hecho, me convertí de repente en profesor encargado, sin haber sido anteriormente ayudante de cátedra. Cuando Bobbio me nombró su ayudante de cátedra, por tanto, yo ya era profesor en Milán: esta anomalía turbó tan profundamente a la administración universitaria, que las oficinas dejaron de pagarme el sueldo. Tuve que irme por casi dos años a la Yale Law School a la espera de que el orden contable fuese restablecido. La elección por la filosofía del Derecho estaba ya más que consolidada, aun cuando me resultaba claro que la universidad y yo tendríamos que actuar siempre según esquemas mentales asimétricos. Mi escaso sentido de la academia se manifestó todavía en 1976, cuando gané el concurso para catedrático en la Italia meridional. Puesto que esa situación geográfica habría hecho difíciles los contactos con Alemania e imposible la edición de la correspondencia de Jhering, ante la consternación de los amigos, renuncié a ser catedrático y permanecí en Milán como profesor asociado. Allí gané después un segundo concurso para catedrático en 1986. Creo por ello que soy el único “catedrático al cuadrado" entre los docentes italianos. 
En conclusión, mi interés por la filosofía del Derecho estuvo bastante claro desde el comienzo, aunque con las oscilaciones debidas a mi dispersa curiosidad intelectual y a los imprevisibles azares de la vida. En particular, las oportunidades interdisciplinarias ínsitas en la filosofía del Derecho me han permitido siempre seguir con mis curiosidades. A veces justifico mis investigaciones más extravagantes con la tesis medio seria de que la filosofía del Derecho no es una disciplina, sino una cátedra desde la que se puede enseñar prácticamente todo.

Si se limita a la secuencia de los eventos, mi vida académica puede parecer un aglomerado de excentricidades. Para ver el plan general es necesario remontarse a los grandes axiomas que rigen incluso las pequeñas vidas, aunque ello me obligue a hacer filosofía en píldoras, como ya ha sucedido hace poco al exponer mi visión del Derecho. En mi vida, las decisiones se organizan, en el fondo, en torno a tres nudos (o axiomas, en el sentido de que los considero como “dados”, innatos, no demostrados): el pensamiento de la muerte, el deseo de saber y el rechazo del poder.

El pensamiento de la muerte es una presencia constante pero no dramática desde la juventud: nunca lo he experimentado como el epílogo de los dolores del joven Werther, sino como "nuestra corporal hermana muerte", de la que San Francisco da gracias a Dios, y como la única certeza de la vida humana. Esta presencia vuelve todo relativo, pero no en el sentido de volverla prescindible: mas bien, todo adquiere importancia porque no puede saberse si al hoy le seguirá un mañana. Se explica así mi anómalo estilo de trabajo: planifico como si fuese eterno, pero trabajo como si tuviese que morir mañana. Antonio Machado ha captado el aspecto más hondo de la contradicción entre la infinidad del saber y la limitación de la vida: "Si tengo que morir / poco me importa aprender. / Y si no puedo saber, / poco me importa vivir”. Pero de hecho prevalece la vida como única posible vía hacia el saber. Mi actitud reproduce así, en cierta medida, la contradicción del protestante que cree en la predestinación, pero trabaja duro para demostrar que ha sido elegido por Dios.

El deseo de saber es para mí una actitud mental totalizadora y sagrada. Por esto, siempre lo he considerado incompatible con cualquier otra actividad. Ni siquiera la carrera académica puede hacerla pasar a un segundo plano, como lo demuestra mi vicisitud de “catedrático al cuadrado”. Me mueve el resorte de conocer e, inmediatamente después, de fijar por escrito lo que he podido aprender: mañana podría ya no estar. No puedo, por el contrario, ser un filósofo (en el sentido etimológico: amigo del saber) de dedicación a medias, fragmentando en actividades diversas mi tiempo ya tan limitado: por tanto, en mi actuar no hay espacio ni para otras profesiones, ni para la 
persecución de la riqueza, ni para la búsqueda de un poder incluso mínimo, como el académico.

En fin, creo que el rechazo del poder es una peculiaridad mía que me pone en una situación de falta de sintonía con la sociedad actual, aturdida por el mito del éxito y, por ello, poseída por el demonio del poder. El poder consiste en la posibilidad de decir a los otros lo que deben hacer, teniendo los medios para obligarlos a obedecer incluso cuando no lo quieran. La conquista del poder propio se paga en términos de libertad (porque se debe descender a pactar con quien es más poderoso) y de tiempo (porque hay que dedicarse a maniobrar para alcanzar, también oblicuamente, el objetivo propio). Puesto que yo deseo tener la libertad total en la búsqueda del saber, y al saber pretendo dedicarle todo el tiempo, me falta del todo el sentido del poder. Esta libertad me ha costado la marginación en mi ex universidad milanesa, dominada más por intrigas de mafiosilllos que por cenáculos de sabios: quien no es un potencial miembro de tribunal en los concursos futuros o un repartidor de fondos no cuenta nada. Habría podido descender a ese mismo terreno, a los habituales ajustes de cuentas entre bandas académicas rivales: ¡pero qué inútil pérdida de tiempo habría sido!

La renuncia al poder tiene la maravillosa capacidad de preservar la pureza de la amistad, otro valor sagrado en mi vida. La amistad entre personas que se unen no por razones de poder son duraderas, porque están fundadas únicamente sobre elecciones afectivas. Además, la elección afectiva no exige que mis amigos hayan también renunciado al poder: cada uno acepta al otro por lo que es. Antes bien, para quien no tienen ningún poder es hermoso tener amigos que hacen carrera.

\section{M.A.: ¿Y qué me dices con respecto al futuro?}

M.L.: Para el futuro he trazado planes como si fuera eterno, con la seguridad de que no llegaré a realizarlos: esta es mi estructura mental que he tratado de explicar poco antes. Como mis colinas en las tardes de verano, estas futuras aventuras intelectuales se dibujan en el horizonte en una sucesión de colores cada vez más difuminados: las más próximas se destacan intensamente azules contra el cielo, mientras que el pálido celeste de las últimas se confunde con el horizonte.

Algunos libros son ya visibles, justamente como las colinas más próximas. El manuscrito del libro sobre el "Movimiento de los Sin Tierra" en Brasil está terminado y se coloca en el surco de los intereses nacidos con Jhering y continuados con las investigaciones sobre el antiformalismo y, en particular, sobre el Derecho alternativo El interés por los Sin Tierra ha nacido justamente de la constatación de que muchas sentencias "creativas" brasileñas nacían para hacer justicia a estos desheredados. De los Sin Tierra 
estoy pasando a los indios, porque los designios benévolos pero abstractos de un lejano gobierno central -a pesar de las esperanzas depositadas en un gobierno que se reclama del Partido de los Trabajadores y está guiado por Lula, ídolo caído hoy sin embargo por tierra- están provocando pequeñas guerras locales entre pobres, en las cuales los indios y los Sin Tierra se disputan los campos no ocupados por los latifundios.

El próximo año meteré mano al libro sobre la modernización jurídica en Turquía, que ya ha tenido dos ediciones en 1980 y 1985, esta última también con una reimpresión en 1990. El volumen había nacido de una curiosidad mía asiática: ¿por qué la occidentalización, me preguntaba, ha dado frutos espectaculares en Japón, pero no en Turquía? Hoy vuelvo a ello, en la onda de una inquietud europea y balcánica: ¿hasta qué punto, me estoy preguntando, la especificidad turca es compatible con la pretendida homogeneidad de la Europa comunitaria? ¿Por qué Turquía venía desde luego bien para la OTAN, pero nunca viene bien para la Unión Europea? La razón de que Turquía no está “en Europa” es inconsistente,

porque tampoco la baña el “Atlántico Norte” al que se refiere el Tratado de cuya organización ya forma parte. Estoy además casi seguro de que esta Europa de contornos tan elásticos me llevará de nuevo a los estudios balcánicos, desde el momento en que Bulgaria y Rumania están por entrar en la Unión Europea, quizás ya en 2007.

Yendo más allá, los contornos del panorama se vuelven más inciertos. En mis planes a larguísimo plazo está una "breve” Historia del Derecho en América latina, para la cual he escrito alguna investigación sectorial y creado una plataforma didáctica. Cuanto más pasa el tiempo, más tengo la impresión de que ese libro no es una meta alcanzable, sino una imagen de Fata Morgana que se aleja a medida que me aproximo.

Por otro lado, no puedo excluir que las incursiones en los diversos campos de las ciencias sociales y de la informática, los acontecimientos externos o los proyectos editoriales me comprometan en actividades en las que hoy no pienso. Lo que es cierto es que hay actividades que no realizaré más o libros que nunca escribiré, porque algunas elecciones vitales de carácter irrevocable las han apartado definitivamente de mi campo de acción. En los años de la adolescencia me tentaba la biología; en los de las inseguridades después de la tesis, la literatura. Hoy se que no escribiré una novela. Tampoco habrá, en los libros de los biólogos, un pececito asiático o una mariposa amazónica que a su nombre añada el apelativo Losanii. Ser joven quiere decir poder elegir, y hoy muchas elecciones están irreversiblemente hechas. Lo que he podido hacer está hecho y lo que no ha sido hecho quizás no se haga ya, aunque no esté dicha la última palabra: según proverbio italiano, “mientras hay vida hay esperanza”. 
Sin embargo, no sólo hay ciencia y libros. También están los sentimientos, las emociones, las impresiones, los lugares del corazón: el impalpable tejido de los recuerdos. Frecuentemente, en sus últimos años, Bobbio me repetía que el paso del tiempo dilata el espacio de los recuerdos y que, mientras el futuro se reduce, el pasado se dilata. Con frecuencia me digo que sería una lástima que mis recuerdos se perdieran cuando yo ya no esté para recordarlos. El saber se salva con los libros; ¿pero los recuerdos? Quien sabe si los recuerdos existen sin quien los recuerda: aunque sea una utopía, sería confortante una recuerdoteca que guardara todos los recuerdos de todos. Sin embargo, aunque la literatura y la poesía asumen en parte esta función, el resto de los recuerdos resulta irremediablemente perdido. Es de nuevo Antonio Machado quien ha encontrado las palabras para expresar este sentimiento: “Cuando recordar no pueda / ¿dónde mi recuerdo irá/ Una cosa es el recuerdo / y otra cosa recordar”.

(Trad. de Manuel Atienza) 
$\triangle \quad$ DOXA 28 (2005) 